\title{
Idiopathic cervical and retroperitoneal fibrosis: report of a case treated with steroids
}

\author{
Peter Husband \\ M.R.C.P., D.C.H. \\ A. KNUDSEN \\ M.D., F.R.C.P., F.R.C.Path. \\ Departments of Paediatrics and Histopathology, West Middlesex Hospital, Isleworth, Middlesex
}

\begin{abstract}
Summary
Retroperitoneal fibrosis in a 12-year-old boy is reported. This was associated with a fibrotic mass in the neck which resolved spontaneously. Right-sided ureteric obstruction responded to treatment with steroids.

\section{Introduction}

Idiopathic retroperitoneal fibrosis was first described by Albarran in 1905 and the first account was published in the English literature by Ormond in 1948. Since then many cases have been described but it is a most unusual disease in childhood. The fibrosis in the retroperitoneal space may be associated with fibrosis in other parts of the body. A case is now described of retroperitoneal fibrosis with ureteric obstruction associated with a fibrotic lesion in the neck occurring in a 12-year-old boy. Following biopsy and treatment with prednisone there was a rapid clinical and radiological improvement.
\end{abstract}

\section{Case report}

A 12-year-old boy was admitted to hospital with a 3-week history of fever, headache, abdominal pain, vomiting and general malaise. On admission he had an intermittent fever which subsided spontaneously after 5 days. The only other abnormal sign was moderate bilateral enlargement of the cervical lymph nodes. His ESR varied between 47 and $75 \mathrm{~mm} / \mathrm{hr}$ and the blood count showed $72 \%$ neutrophils of $5800 \mathrm{WBC} / \mathrm{mm}^{3}$ and $84 \%$ neutrophils of 11,300 $\mathrm{WBC} / \mathrm{mm}^{3}$ on two occasions.

He was seen by one of the authors (P.H.) 6 weeks after the onset of his illness. He was an ill looking boy weighing $54 \mathrm{~kg}$. There was now a hard mass in the left anterior triangle of the neck which felt like enlarged nymph nodes. He had a left ptosis with mild periorbital erythema. There was no proptosis, external ocular muscle paresis or pupillary abnormality. His abdomen was tense and difficult to palpate but there was a suggestion of a hard craggy mass in the right hypochondrium and right lumbar regions. On clinical grounds a provisional diagnosis of malignant lymphoma was made and a biopsy of the cervical mass was therefore carried out.

Histology. The biopsy consisted mainly of young of proliferating fibroblastic tissue sparsely infiltrated by lymphocytes and eosinophil leucocytes. Plasma $\vec{\perp}$ cells and neutrophil polymorphs were absent. Small areas of fibrinoid degeneration were present in the $\infty$ young fibrous tissue. Blood vessels were few and the 은 appearance did not resemble granulation tissue. There was no evidence of vasculitis. One small lymph node was present. This showed sinus cell hyperplasia $\varnothing$ and infiltration of the medulla by plasma cells 3 Follicular pattern was preserved and germinal centres were prominent. There was no evidence lymphoma.

Under the anaesthetic what was thought to be a extensive mass of retroperitoneal glands was felt in the epigastrium and down the right side of the aorta.

As the neck biopsy was not diagnostic a $\overline{0}$ laparotomy was performed 3 days later. The intraperitoneal viscera were normal but the retro- $\stackrel{\varnothing}{\varrho}$ peritoneal space was grossly abnormal. There was a $\overrightarrow{\overrightarrow{0}}$ pearly white thick indurated mass extending from the 3 bifurcation of the iliac vessels on the right up to the level of the duodenum. It extended across the midline covering the great vessels and went down to the $\overline{0}$ pelvic brim on the left. Laterally it extended from 3 beyond the outer border of the right psoas muscle, $\frac{5}{3}$ across to the outer border of the left psoas. There were a number of prominences suggestive of enlarged $ᄋ$ lymph nodes but incisions into these areas showed only abnormal connective tissue and discrete nodes 옥 were not apparent. A number of biopsies from $D$ various sites were taken.

Histology. The retroperitoneal tissue resembled $\bar{N}$ the neck biopsy, consisting of young proliferating or fibroblastic tissue sparsely infiltrated by lympho- 0 cytes and eosinophils (Fig. 1). Plasma cells and $\underset{\omega}{ }$ neutrophil leucocytes were extremely scanty. Some infiltration of fat was seen but foam cells were not 0 present. Three tiny lymph nodes were included and $\Phi$ these showed mild sinus cell hyperplasia but no other $\stackrel{?}{?}$ abnormality. 


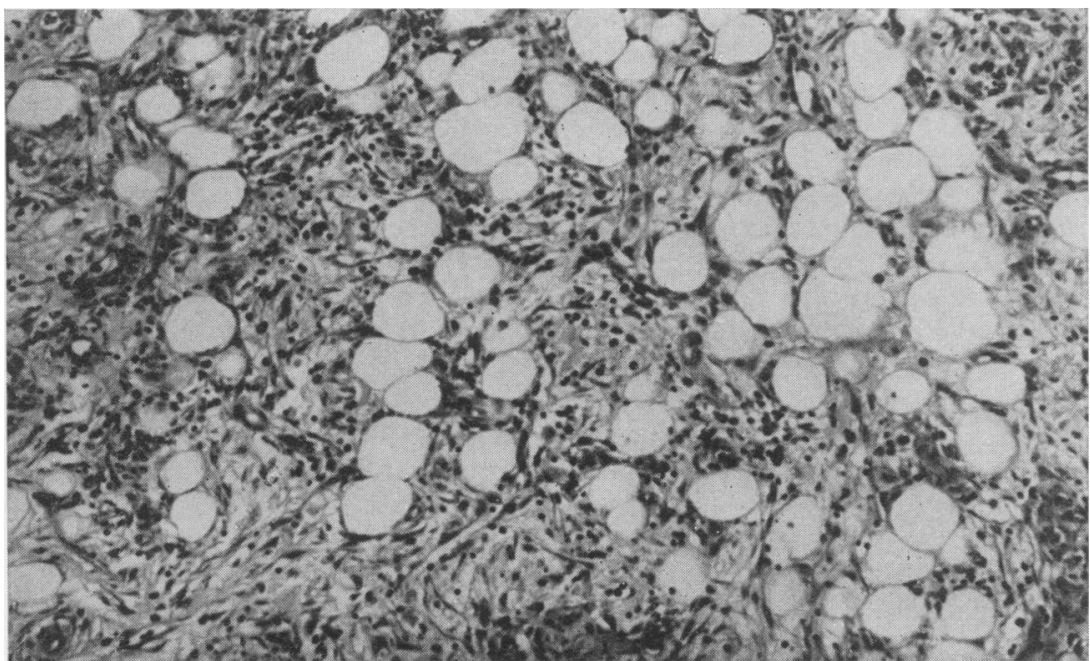

FIG. 1. Retroperitoneal tissue. Magnification $\times 128$, showing replacement of fat by proliferating fibrous tissue with sparse infiltration by chronic inflammatory cells.

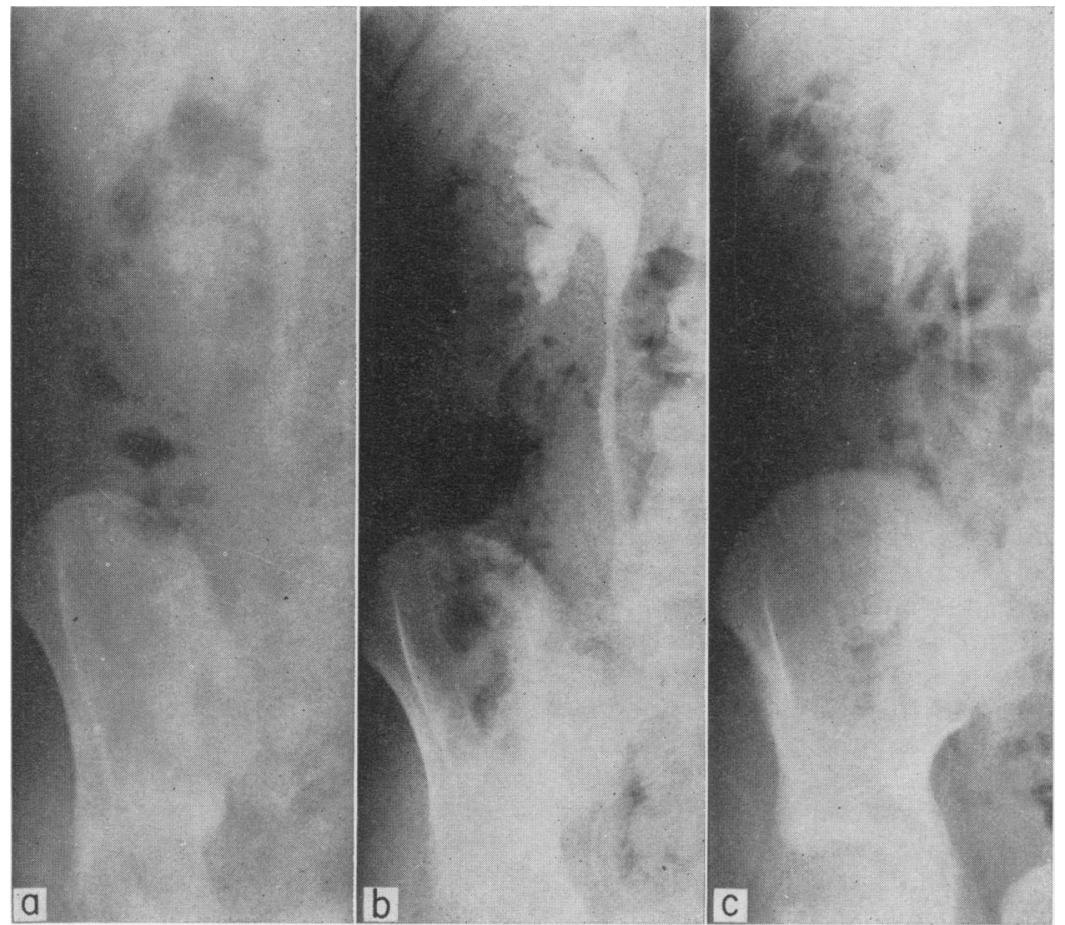

FIG. 2. (a) View of the right kidney and ureter. The ureter is obstructed at the lumbar 4/5 disc level and there is slight medial deviation just above the point of obstruction with abrupt tapering of the ureter. (b) After 2 weeks' treatment with prednisone. The hydronephrosis is unchanged but the ureter is now less dilated. (c) After 4 months there is a normal appearance of the right kidney and ureter. 
In view of the clinical and histological findings of retroperitoneal fibrosis, an intravenous urogram was done (Fig. 2a). The right kidney was $15.2 \mathrm{~cm}$ and the left $13.5 \mathrm{~cm}$ in length. There was moderate dilatation of the right calyces, pelvis and ureter, the latter being dilated down as far as the lumbar 4/5 disc level. The ureter beyond was not visualized. There was no detectable reduction in the renal parenchymal width. The left kidney and collecting system and bladder appeared normal. Urine culture was sterile and the plasma creatinine was $0.4 \mathrm{mg} / 100 \mathrm{ml}$.

Other investigations showed no underlying cause for the retroperitoneal fibrosis.

Bone marrow, normal, apart from a non-specific increase in lymphocytes and a few large atypical mononuclear cells;

Blood culture, sterile;

Salmonella agglutination titres, $<1 / 25$;

Brucella abortus agglutination titre, $<1 / 10$;

WR and VDRL, negative;

Toxoplasma cytoplasm-modifying antibody titre, $1 / 128$;

Plasma proteins, total $6 \mathrm{~g} / 100 \mathrm{ml}$; albumin $3 \mathrm{~g} /$ $100 \mathrm{ml}$;

Protein electrophoresis, non-specific increase in the $\alpha_{1}$ - and $\alpha_{2}$-globulins;

Immunoglobulins $/ 100 \mathrm{ml}, \mathrm{IgG}, 1162 \mathrm{mg}$; IgA, 290 mg; IgM, $128 \mathrm{mg}$;

Immunofluorescent antibody tests: Thyroid colloid

Thyroid epithelial cell cytoplasm

Gastric parietal cell cytoplasm

Nuclei (ANF)

Mitochondria

Smooth-muscle

Nitro-blue tetrazolium test: Normal

Oral prednisone $60 \mathrm{mg} /$ day was started 10 days after the cervical biopsy. By this time the fibrous mass in the neck had already shrunk remarkably and his ptosis was improving. Two weeks after starting treatment a second intravenous urogram was done (Fig. 2b). This showed no change in the length of the right kidney. There was no definite change in the degree of hydronephrosis but the right ureter was now less dilated. There was no evidence of obstruction at the lumbar $4 / 5$ disc level but moderate dilatation of the ureter extended to the L5 S1 vertebral level. Beyond this, the ureter of normal calibre was outlined. Prednisone was continued for 8 weeks in all and a third intravenous urogram was performed 4 months after the first (Fig. 2c). The right kidney was now appreciably smaller $(12.6 \mathrm{~cm})$ and appeared completely normal. The collecting system was normal and there was no evidence of ureteric obstruction.

When last seen 1 year after the onset of his illness, the patient was extremely well, with no abnormal signs except for some keloid in the two operation 3 scars. His ESR was $10 \mathrm{~mm} / \mathrm{hr}$.

\section{Discussion}

Idiopathic retroperitoneal fibrosis is usually $a \stackrel{\text { ? }}{\stackrel{9}{9}}$ disease of middle age and is a rarity in childhood. Packham and Yates-Bell (1968) found only two $\overline{\bar{c}}$. cases in children under the age of 10 years in a review $\frac{\widehat{\sigma}}{\widehat{\sigma}}$ of 130 cases. It was first reported in childhood byळ Farrer and Peterson (1962). They described an 8year-old girl with a 3-week history of left flank pain. $\vec{\circ}$ The obstructed left ureter was freed by ureterolysis: and her subsequent course was satisfactory with a $\vec{\omega}$ normal intravenous urogram 18 months later $\frac{D}{8}$ Peterson, Besecker and Hutchison (1974) reported $a 0$ further case in an 8-year-old girl where the pre senting symptom was gluteal pain. Extensive retro- $N$ peritoneal fibrosis was found in a 30-week stillbirth 9 (Duffy, 1966). Ischaemic atrophy of the left kidney: had followed involvement of the left ureter and renaloo vessels in the fibrotic process.

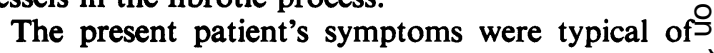
those in older people. Abdominal pain is the most ${ }^{-}$ common presenting symptom (Packham and Yates- $\mathbb{\Phi}$ Bell, 1968). The same authors reported weight-loss in $33 \%$ of cases, vomiting in $22 \%$ and generlo malaise in $22 \%$. The disease may present with믄 urinary symptoms and anuria occurs in $15 \%$ cases. Oedema of the legs due to inferior vena cavalo obstruction may also occur.

The cause of retroperitoneal fibrosis is in mosto instances unknown and laboratory investigations usually show non-specific abnormalities. As in thiso patient, there is often a leucocytosis, elevated ESR, and non-specific increase in the globulin fraction of $\mathcal{O}^{-}$ the plasma proteins (Packham and Yates-Bell, $\overrightarrow{\overrightarrow{0}}$ 1968). Ureteric obstruction is the most common functional effect of retroperitoneal fibrosis and can be demonstrated radiologically. It is frequently stated that medial deviation of the obstructed ureter? is characteristic of this condition but the significanceof this has been questioned by Saldino and Palubinskas (1972) and Arger, Stolz and Miller (1973). Ingestion of methysergide is a well recognized cause of retroperitoneal fibrosis (Graham et al., 1966). Brown et al. (1964) have suggested that it may be the result of partially treated infections, thus accountingo for its being rarely recognized in the pre-antibiotic era. However, except when secondary to a localer infection such as diverticulitis, there is little evidencen for an infective origin.

The diagnosis can only be made with reasonable $e^{\omega}$ certainty when supported by histological evidence. The microscopical appearances vary considerably Early lesions usually show considerable fat and loose fibrous tissue with relatively little collagen and numerous plump fibroblasts. Later lesions tend to be 
denser and less cellular with hyaline fibrous tissue which may show areas of calcification. Considerable variation may be seen between multiple biopsies taken at different sites. Particularly in early lesions muco-polysaccharide may be demonstrable between the collagen fibres. Fibrinoid areas may also be encountered. Inflammatory cells vary greatly in number and are sparse in areas of dense fibrosis. The infiltrate typically consists of lymphocytes, plasma ceils and eosinophils. Neutrophils are usually few or absent. Focal masses of lymphocytes may be present, sometimes with well formed germinal centres. Where the proliferating fibrous tissue is infiltrating, fat foamy histiocytes are sometimes seen. In the majority of patients the histological picture, radiological studies and clinical features together serve to establish the diagnosis. Fibrosis secondary to diverticulitis or other local inflammatory lesions can usually be excluded without difficulty. The main diagnostic problem is the identification of those cases in which the fibrosis is a reaction to underlying lymphoma or secondary carcinoma of the paraaortic nodes. Buckberg, Dilley and Longmire (1966) reported fifteen patients with eleven ureters involved, in whom the clinical appearances, initial laparotomy and biopsy findings represented classical idiopathic retroperitoneal fibrosis. Four of the patients ultimately proved to have neoplastic disease.

For the pathologist, the presence of heavy lymphoid infiltration in the biopsy, particularly if germinal centres are absent, may raise the suspicion of lymphosarcoma but definite diagnosis may not be possible. The blood picture, marrow examination and lymph node biopsy may be diagnostic but in some cases a prolonged period of observation proves necessary.

It is now widely considered that idiopathic retroperitoneal fibrosis should be classed as one of the collagen diseases (Pugh, 1960; Saxton et al., 1969). The condition is inflammatory, affects connective tissues and may be associated with fibrosis in many parts of the body, suggesting a systemic disorder rather than a local abdominal disturbance. The condition is steroid-sensitive and may be associated with arthritis or arteritis similar to rheumatoid disease. In most cases the fibrosis extends from the second lumbar vertebra to the aortic bifurcation but can extend to involve the mediastinum (Packham and Yates-Bell, 1968), the orbit (Jackson, 1958) or the thyroid (Hache, Utz and Woolner, 1962). Mitchinson (1970) reviewed forty cases of retroperitoneal fibrosis and found Reidel's thyroiditis in two of them. In this condition there is fibrosis of the thyroid gland as well as adjacent structures including muscle. Although in the present patient there was an extensive fibrotic lesion in the neck there was no clinical or biochemical evidence of thyroid involvement.
Cases have also been reported with involvement of the heart (Reed and Stinely, 1959), epididymis (Ardagh and Blake, 1964) and the testis (Cameron et al., 1961).

The concept of a collagen disease is supported by the occurrence of non-inflammatory fibromatoses in this condition. Keloid occurred in both scars in the present patient and has also been reported by Hellstrom and Perez-Stable (1966) and Que and Mandema (1962). Raper (1960) comments on the histological similarity to the late stage of polyarteritis and Benfield et al. (1962) described a case in association with bilateral nodular pulmonary granulomatosis simulating Boeck's sarcoidosis. Ormond (1965) thinks that this condition is an immunological disorder, being a hypersensitivity reaction to an unknown allergen and that a vasculitis is the primary event. Widespread vasculitis has been recorded by Hellstrom and Perez-Stable (1966) and Reidbord and Hawk (1965). Mitchinson (1970). in a postmortem study of forty cases, found evidence of an acute vasculitis in one case and more chronic lesions in a further eight. One patient showed a polyarteritis-like lesion. The significance of the chronic vascular lesions is doubtful. In some cases they may well be secondary to involvement of vessels by the extending fibrosis. Arteritis is rarely seen in biopsy material. The family reported by Phills et al. (1973) suggests an immunological disorder. They described retroperitoneal fibrosis in three siblings all having the sickle-cell trait. They all shared a moderate polyclonal hyperglobulinaemia. In the first case immunofluorescent studies showed deposits of immunoglobulins IgG and IgM, as well as fibrin in a granular pattern along the basement membrane of small vessels.

The treatment of an established case of retroperitoneal fibrosis is usually by surgical release of the ureter from the surrounding dense scar tissue. However, the results of surgery are variable (Ollson $e t$ al., 1962; Jose, 1967; Kerr et al., 1968). Steroids might be expected to be effective in this condition because of their powerful anti-inflammatory effect and their effect in inhibiting the maturation of fibrous tissue. The response to steroids should be better in patients such as the present one where the histology suggests an early stage of the disease rather than progression to a hyaline fibrotic stage. The unpredictable course of this disease makes evaluation of steroid therapy difficult. It is impossible to observe the natural history of this disease as surgery is mandatory if only to obtain a biopsy for histological confirmation of the diagnosis. There is good evidence that biopsy alone can result in improvement (Mahoney and Edwards, 1962; Wright and Sanders, 1971). There was no doubt that the fibrous mass in the neck of this boy started to shrink rapidly after biopsy and before 
steroids were given. Prednisone has been used in conjunction with surgery with no evidence of recurrence of obstruction to the transplanted ureters (Hywel Jones et al., 1970). However, steroid therapy can adequately be assessed only when the renal tract has not been subjected to surgery. When steroids are used immediately following a biopsy as in the present case and those of Hawk and Hazard (1959), Ollson et al. (1962) and the second case of Morandi and Grob (1971), one cannot be sure how much benefit is due to the biopsy alone. The pure effect of steroids is better seen in those cases with an initial biopsy in which recurrences of the disease have been treated with steroids with rapid improvement (Shaheen and Johnston, 1959; O’Regan, Treahy and Prior, 1961 ; Rust and Maas, 1967; and the first case of Morandi and Grob, 1971). In the present case, radiological improvement was seen after two weeks of steroid therapy. This rapid response supports the view that the ureter is obstructed by oedema and inflammation (Mitchinson, 1970).

\section{Acknowledgments}

We thank Dr S. G. Lamb for referring this child to us. Mr D. E. Bolt performed the surgery. We are grateful to Professor J. F. Soothill for the NBT test.

\section{References}

Albarran, J. (1905) Retention rénale par périurétérite et libération externe de l'urétère. Association française d'urologie, 9, 511.

ARdaGH, J.W. \& Blake, G.B. (1964) Idiopathic retroperitoneal fibrosis. New Zealand Medical Journal, 63, 362.

Arger, P.H., Stolz, J.L. \& Miller, W.T. (1973) Retroperitoneal fibrosis: an analysis of the clinical spectrum and roentgenographic signs. American Journal of Roentgenology, Radiotherapy and Nuclear Medicine, 119, 812.

Benfield, J.R., Harrison, R.W., Moulder, P.V., Lyon, E.S. \& GRAFF, P.W. (1962) Bilateral nodular pulmonary granulomas and retroperitoneal fibrous simulated metastatic malignant neoplasm and spontaneous remission of ureteral obstruction. Journal of the American Medical Association, 182, 579.

Brown, K.A., Staubitz, W.J., Oberkircher, O.J. \& Niesen, W.C. (1964) A review of retroperitoneal fibrosis. Journal of Urology, 92, 323.

Buckberg, G.D., Dilley, R.B. \& Longmire, W.P. (1966) The protean manifestations of sclerosing fibrosis. Surgery, Gynecology and Obstetrics with International Abstracts of Surgery, 123, 729.

Cameron, D.G., Ing, S.T., Boyle, M. \& Mathews, W.H. (1961) Idiopathic mediastinal and retroperitoneal fibrosis. Canadian Medical Association Journal, 85, 227.

DUfFY, J.L. (1966) Fetal retroperitoneal fibrosis associated with hydramnios Journal of the American Medical Association, 198, 993.

Farrer, J. \& Peterson, C.G. (1962) Idiopathic retroperitoneal fibrosis. Report of first case observed in a child. Pediatrics, 30, 225.

Graham, J.R., Suby, H.T., Lecompte, P.R. \& Sadowsky, N.L. (1966) Fibrotic disorders associated with methysergide therapy for headache. New England Journal of Medicine, 274, 359.
HAChe, L., Utz, D.C. \& WoolneR, L.B. (1962) Idiopathic fibrous retroperitonitis. Surgery, Gynecology and Obstetrics $\stackrel{\unrhd}{\varrho}$ with International Abstracts of Surgery, 115, 737.

HAWK, W.A. \& HAZARD, J.B. (1959) Sclerosing retroperitonitis and sclerosing mediastinitis. American Journal of $\overline{\overline{\overrightarrow{ }}}$ Clinical Pathology, 32, 321.

Hellstrom, H.R. \& Perez-Stable, E.C. (1966) Retroperitoneal fibrosis with disseminated vasculitis and intra-흐 hepatic sclerosing cholangitis. American Journal of Medi- $\overline{\bar{S}}$ cine, 40, 184.

Hywel Jones, J., Ross, E.J., Matz, L.R., Edwards, D. \& $\varrho$ DAvies, D.R. (1970) Retroperitoneal fibrosis. American Journal of Medicine, 48, 203.

JACKSON, H. (1958) Pseudo-tumour of the orbit. British $\vec{\circ}$ Journal of Ophthalmology, 42, 212.

Jose, J.S. (1967) Idiopathic retroperitoneal fibrosis. Notes on $\vec{\omega}$ its diagnosis, management and pathogenesis. British Journal of Urology, 39, 431.

Kendall, A.R. \& LaKey, W.H. (1961) Sclerosing Hodgkin's disease vs. idiopathic retroperitoneal fibrosis. Journal of $\mathrm{v}$ Urology, 86, 217.

KerR, W.S., SUby, H.I., Vickery, A. \& Fraley, E. (1968) Idiopathic retroperitoneal fibrosis: clinical experiences $\vec{A}$ with 15 cases, 1956-67. Journal of Urology, 99, 575.

MaHONEY, E.M. \& EdwardS, E.A. (1962) Spontaneous $\infty_{\infty}^{\infty}$ regression of leg edema and hydronephrosis followingo idiopathic retroperitoneal fibrosis. American Journal of Surgery, 103, 514.

Mitchinson, M.J., Withycombe, J.F.R. \& ARden Jones, R. (1971) The response of idiopathic retroperitoneal fibrosis to corticosteroids. British Journal of Urology, 43, 444.

Mitchinson, M.J. (1970) The pathology of idiopathic ret peritoneal fibrosis. Journal of Clinical Pathology, 23, 68. 음

MORANDI, L.P. \& GROB, P.J. (1971) Retroperitoneal fibroses. $\overrightarrow{1}$ Response to corticosteroid therapy. Archives of Interkig Medicine, 128, 295.

Ollson, S., SJoberg, J.E., WAHLQuist, L. \& Zederfeldt, (1962) Idiopathic retroperitoneal fibrosis. Acta chirurgica scandinavica, 123, 427.

ORMOND, J.K. (1948) Bilateral ureteral obstruction due to envelopment and compression by an inflammatory retro-ฏ peritoneal process. Journal of Urology, 59, 1072.

ORMOND, J.K. (1965) Idiopathic retroperitoneal fibrosis: a discussion of the etiology. Journal of Urology, 94, 385.

ORMOND, J.K. (1967) In: The Ureter (Ed. by H. Bergman), p. 300. Harper and Row, New York.

O'Regan, R., TreaHY, P.A. \& Prior, I.A.M. (1961) Idiopathic retroperitoneal fibrosis. A case presenting with renal failure, treated effectively with adrenal steroids. New Zealand Medical Journal, 60, 518.

Packham, D.A. \& Yates-Bell, J.G. (1968) The symptoma-ס̈ tology and diagnosis of retroperitoneal fibrosis-a review and presentation of case reports. British Journal of Urology, 40, 207.

Peterson, A.S., Besecker, J.A. \& Hutchison, W.A. (1974) Retroperitoneal fibrosis and gluteal pain in a child. Journalo of Pediatrics, 85, 228.

Phills, J.A., Geggie, P., Htovegi, R.I. \& Oliva, L.A. (1973) Retroperitoneal fibrosis in three siblings with the sicklecell trait. Canadian Medical Association Journal, 108, 1025. $\mathrm{N}$

Pugh, R.C.B. (1960) The pathology of fibrotic lesions. ज Proceedings of the Royal Society of Medicine, 61, 875. N

QUE, G.S. \& MANDEMA, E. (1962) A case of idiopathic retro-은 peritoneal fibrosis presenting as a systemic collagen $\omega$ disease. American Journal of Medicine, 36, 320.

RAPER, F.P. (1960) Idiopathic retroperitoneal fibrosis in volving the ureters. Proceedings of the Royal Society of Medicine, 53, 690.

ReEd, W.G. \& Stinely, R.W. (1959) Massive periaortic and $\stackrel{\oplus}{+}$ periarterial fibrosis. New England Journal of Medicine, 261, 320. 
Reidbord, H.W. \& HaWk, W.A. (1965) Idiopathic retroperitoneal fibrosis and necrotizing vasculitis. Report of a case with autopsy findings and etiologic considerations. Cleveland Clinic Quarterly, 32, 19.

RusT, J.A. \& MAAS, H.E. (1967) Pelvic retroperitoneal fibrosis with response to prednisolone. American Journal of Obstetrics and Gynecology, 98, 654.

Saldino, R.M. \& Palubinskas, A.J. (1972) Medial placement of the ureter: a normal variant which may simulate retroperitoneal fibrosis. Journal of Urology, 107, 582.

Saxton, H.M., Kilpatrick, F.R., Kinder, C.H., Lessof,
M.H., Mchardy-Young, S. \& Warole, D.F.H. (1969) Retroperitoneal fibrosis. A radiological and follow-up study of fourteen cases. Quarterly Journal of Medicine, 38, 159.

ShaheEn, D.J. \& Johnston, A. (1959) Bilateral ureteral obstruction due to envelopment and compression by an inflammatory retroperitoneal process: report of two cases. Journal of Urology, 82, 51.

WRIGHT, F.W. \& SANDERS, R.C. (1971) Is retroperitoneal fibrosis a self-limiting disease? British Journal of Radiology, 44, 511 .

\title{
Phaeochromocytoma with unilateral renal artery stenosis
}

\author{
C. Thomas \\ M.D. \\ R. K. KOLHATKAR
F.R.C.S.
}

N. L. SHARMA

M.D., F.R.C.P.(E)

S. G. DEODHARE

M.D., F.C.P.S.

Wanless Hospital, Miraj Medical Centre, Miraj, India

\begin{abstract}
Summary
A patient with renal artery stenosis due to compression by a phaeochromocytoma is described. He underwent nephrectomy and tumour removal successfully.

\section{Introduction}

The two common causes for renovascular hypertension are atherosclerosis and fibromuscular hyperplasia (Foster et al., 1975). Rarely, tumours adjacent to the hilum of the kidney may compress the renal artery and produce hypertension. Weidmann et al. (1969) reviewed seventeen such cases, and found phaeochromocytoma to be the most common tumour, occurring in eleven cases. Since then three further cases of phaeochromocytoma and renal artery stenosis have been reported (McBride and Fitz, 1971; Kaufman, Marks and Smith, 1974; Schwartz et al., 1974). In this paper, one case of phaeochromocytoma with unilateral renal artery stenosis is reported.

\section{Case report}

A 31-year-old man was admitted with chest pain and giddiness. Hypertension had been first detected 6 years previously at another hospital and the patient was taking anti-hypertensive drugs irregularly. On examination, his supine blood pressure was 250/180

Correspondence: Dr C. Thomas, Wanless Hospital, Miraj Medical Centre, Miraj (Maharashtra), India.
\end{abstract}

mmHg. Cardiovascular, respiratory and central nervous systems were normal. Optic fundi revealed narrowing of the arterioles and $a-v$ nipping. No abdominal bruit was heard.

Investigations gave the following results: $\mathrm{Hb} \mathbf{1 7 . 9}$ $\mathrm{g} / 100 \mathrm{ml}$; WCC $6000 / \mathrm{mm}^{3}$; blood urea $30 \mathrm{mg} / 100$ $\mathrm{ml}$; blood sugar $85 \mathrm{mg} / 100 \mathrm{ml}$; serum creatinine 1.0 $\mathrm{mg} / 100 \mathrm{ml}$, serum sodium $127 \mathrm{mEq} / \mathrm{l}$; serum potassium $3.7 \mathrm{mEq} / \mathrm{l}$. An intravenous phentolamine hydrochloride test caused a drop in systolic pressure of $40 \mathrm{mmHg}$, and a drop in diastolic pressure of $\mathbf{3 0}$ mmHg. Presacral air insufflation followed by a rapid sequence intravenous pyelogram revealed an irregular, poorly functioning, contracted right kidney. The left kidney appeared normal and no adrenal tumour was seen. Translumbar aortography showed a normal left renal artery, but the right renal artery was not visible and appeared occluded at its origin (Fig. 1). At operation, the right kidney was contracted and a tumour was found adherent to the hilum (Fig. 2). Dissection proved difficult and a nephrectomy was performed. The blood pressure fell immediately and the patient required vasopressors for several hours. The kidney measured $6 \times 3.5 \mathrm{~cm}$ and weighed $32 \mathrm{~g}$, while the tumour measured $4.5 \times$ $3 \mathrm{~cm}$ and weighed $26 \mathrm{~g}$. Microscopic examination of the tumour revealed cells typical of phaeochromocytoma. Microscopic examination of the kidney showed hyalinization of the glomeruli, and 